\title{
Percepção e Enfrentamento do Psicossomático na Relação Médico-Paciente ${ }^{1}$
}

\author{
Vera Lucia Pereira Alves ${ }^{2}$ \\ Espaço de Estudos e Pesquisas na Abordagem Centrada na Pessoa \\ Daniela Dantas Lima \\ Universidade Estadual de Campinas
}

\begin{abstract}
RESUMO - Com o objetivo de compreender a vivência de médicos no atendimento a pacientes psicossomáticos, foi realizada uma pesquisa qualitativa e fenomenológica com quatro profissionais da medicina. A compreensão das entrevistas mostra que as condutas perfazem um percurso iniciado por um diagnóstico, seguido de uma mobilização pessoal que os conduz a tentativas de reorganizar a relação médico-paciente e a utilizar algumas terapêuticas, bem como demonstram seu despreparo na abordagem do tema. Esse percurso é compreendido de acordo com o modelo biomédico que rege as concepções e práticas apreendidas desde a graduação. No entanto, essa formação gera dificuldades no manejo de aspectos psicológicos, e não apenas dos referidos como elementos psicogênicos do adoecimento, típicos das compreensões psicossomáticas. Evidencia-se uma aprendizagem médica em que se dá mais atenção à doença do que ao ser que adoece.
\end{abstract}

Palavras-chave: medicina psicossomática, medicina, doença psicossomática, educação médica, psicologia médica, relação médico-paciente

\section{Perceiving and Facing the Psychosomatic in the Physician-Patient Relationship}

\begin{abstract}
With the objective to understand the medical experience in attending psychosomatic patients, a qualitative and phenomenological research was carried on with four doctors. The comprehension of their reports shows that their conduct makes a course beginning at the diagnostic, followed by a personal mobilization which leads them to reorganize their relations with the patients and the offered therapeutics, as also how they reveal their lack of qualification to approach this subject. This course is understood in accordance with the biomedical model referred as the regent of their conceptions and practices, since medical undergraduate education. However, this formation brings them difficulties to manage the psychological aspects, not only the psychogenic ones related to the sickness, typical from psychosomatics comprehensions. It is evidenced a medical learning in which it is given more attention to illness than to human experience.
\end{abstract}

Keywords: psychosomatic medicine, medical sciences, psychosomatic disorders, medical education, medical psychology, physician-patient relationship

O tratamento de um adoecimento pela medicina iniciase, via de regra, pela busca de suas causas. O tratamento a ser traçado depende, assim, de um diagnóstico, sendo este necessário também para o estabelecimento de um prognóstico. De buscas por causas consideradas de ordem sobrenatural na Antiguidade, a medicina evoluiu para uma postura científica em que as tecnologias se tornaram primordiais para o estabelecimento dos diagnósticos (Volich, 2005).

Todavia, quando, na atualidade, plena de recursos materiais, a medicina se defronta com adoecimentos sem causas explicitas, instaura-se, segundo Zorzanelli (2011), um campo problemático, em que o médico se vê em um impasse sem diagnóstico e o paciente, sem uma causa explicável para seu sofrimento. Esse campo etiológico, segundo a mesma autora, constitui um "território de controvérsia na história da medicina desde o fim do século XVIII" (Zorzanelli, 2011, p. 26), pois fazem parte dele, além de doenças sem lesões, as doenças com causas pouco mensuráveis, como, por exemplo, as decorrentes de eventos estressores. Tais doenças,

1 Agradecimentos: Gostaríamos de agradecer a participação da psicóloga Tatiana Espinha que, no início desta pesquisa, foi responsável pelas entrevistas.

2 Endereço para correspondência: Av. Júlio de Mesquita 536, Apto. 32 , Campinas, SP, Brasil. CEP: 13.025-061.E-mail: vera@alves.com.br em que os aspectos emocionais se fazem presentes como elemento de origem e/ou evolução, têm sido nomeadas por psicossomáticas (Cerchiari, 2000; Turato, 2008; Zorzanelli, 2011).

O termo psicossomática surgiu em 1818 com os estudos de Heinroth (Aisenstein, 2008; Cerchiari, 2000; Figueira \& Ouakinin, 2008; Lyketsos, Huyse, Gitlin, \& Levenson, 2006, Volich, 2005). Entretanto, não foi utilizado até o início do século XX (De Marco, 2003; Lyketsos et al., 2006), quando foi reintroduzido por Deustsch, em 1922 (Hoyos, Ochoa, \& Londoño, 2008; Lyketsos et al., 2006;Turato, 2008, Volich, 2005), que, associado a Groddeck e Ferenczi, desenvolveu estudos em estreita ligação com os princípios da teoria psicanalítica, sendo, por isso, considerados os desenvolvedores da psicossomática nessa abordagem (Aisenstein, 2008; Cerchiari, 2000). A proximidade com a psicanálise, mesmo que Freud nunca tenha escrito sobre o tema, é creditada via o conceito de conversão por ele delineado, assim como à tentativa de superação do mesmo como modelo de compreensão para o sintoma somático (Turato, 2008; Volich, 2005).

$\mathrm{Na}$ década de 1930, os psicanalistas europeus que se mudaram para os Estados Unidos criaram o Instituto de Medicina Psicossomática de Chicago. Franz Alexander, representante desse instituto, lança em 1950 o livro 
Psychosomatic Medicine, em que expressa a concepção de que a doença psicossomática decorreria de conflitos internos que, se não plenamente elaborados, seriam expressos pela via corporal (Cerchiari, 2000; Turato, 2008; Volich, 2005). Para Alexander, seria importante considerar o organismo como uma unidade, incluindo também a personalidade do doente. Segundo Turato (2008), essa concepção denota sua semelhança à hipótese dos perfis psicossomáticos delineados por Flanders Dunbar em 1943, no livro Psychosomatic Diagnosis, em que perfis específicos são associados a aspectos psicológicos subjacentes a algumas doenças. Desse modo, Alexander defendia a individualização da terapêutica desses pacientes segundo suas psicodinâmicas, criticando atitudes médicas que refutassem abordagens psicológicas por considerá-las estranhas à medicina e criticando igualmente tentativas organicistas de substituir conhecimentos psicodinâmicos por hipóteses de processos cerebrais e fisiológicos para a doença em questão. Segundo Volich (2005), as ideias de Alexander marcam até hoje os estudos de psicossomática em quase todas as especialidades médicas, orientando-as para a investigação de mecanismos individuais que transformam qualquer doença em único recurso possível para a superação de conflitos internos do sujeito.

Na década de 1970, em Paris, Pierre Marty, Michel de M'Uzan, Michel Fain e Chistian David fundam a Escola de Psicossomática de Paris. Eles partem da abordagem psicanalítica, notadamente de sua concepção de metapsicologia, e vão além dela ao introduzir novas hipóteses decorrentes da exploração de aspectos psicológicos presentes nas doenças orgânicas. Para eles, o aparelho psíquico regularia o funcionamento psicossomático, mas não de forma previsível, pois concebiam a atividade mental pautada pelo princípio da irregularidade (Peres, Caropreso, \& Simanke, 2015). No entendimento de Mello Filho (2002), as ideias inspiradas na psicanálise constituem a primeira de três fases do desenvolvimento da psicossomática.

A segunda fase, composta pela vertente psicofisiológica, concebe a doença psicossomática como um "resíduo filogenético das respostas habituais de um organismo em face das situações encontradas nas suas relações com o ambiente" (Volich, 2005, p. 99). Por meio de estudos experimentais, os fisiologistas buscam encontrar as bases para explicar, entre as várias reações, por exemplo, aquelas que consideram apontar fragilidade quanto às expressões simbólicas encontradas frequentemente em pacientes psicossomáticos: as referidas à expressão verbal e às decorrentes de dificuldades intelectuais para expressar emoções (Volich, 2005).

Para o fisiologista Walter Cannon, que cunhou o conceito de homeostase, os animais, quando sob estímulos que desiquilibram a homeostase, preparam-se para luta ou fuga com alterações somáticas oriundas de alterações fisiológicas (Cerchiari, 2000). Igualmente afeito a essa teoria, Hans Selye, através do conceito de estresse tomado da física, caracteriza-o como desencadeado pela presença de elemento que, real ou imaginário, de forma aguda ou crônica, leva o indivíduo a uma resposta inespecífica (Cerchiari, 2000; Volich, 2005). Essa abordagem psicofisiológica agrupa estudos sobre a ação orgânica de mecanismos neurofisiológicos, neuroendocrinológicos e imunológicos decorrentes de estados mentais.
A terceira e atual fase estaria sublinhada por uma multidisciplinaridade. Trata-se de uma postura que visa compreender aspectos sociais e integrar os estudos de profissionais de diversas áreas de saúde na compreensão desta conexão (Cerchiari, 2000; Mello Filho, 2002).

Os estudos realizados em todas as fases supracitadas podem ser igualmente compreendidos como fundamentados na noção ou de psicogênese ou de holismo, segundo Lipowski (1986). A vertente da psicogênese - condenada pelo autor por ser incompatível com a multicausalidade, que é o pressuposto da terceira fase na concepção de Mello Filho - tem por pressuposto que fatores psicológicos causam doenças orgânicas, sendo, desse modo, uma concepção alinhada ao dualismo cartesiano, uma vez que focaliza predominantemente o corpo (De Marco, 2003; Hoyos et al., 2008). Sob essa vertente, a psicossomática, que, em sua origem, seria uma oposição ao dualismo, não cumpre esse objetivo.

O paradigma cartesiano é considerado a principal influência a alicerçar toda a moderna medicina. A ideia seminal é a separação mente/corpo. O corpo, explicado como na mecânica, é comparado a uma máquina, enquanto a mente, separada, dá movimento a esse corpo, contudo, vista também de maneira mecânica. Segundo Descartes, haveria interação entre essas partes, porém de difícil e desarmônica união (Heidbreder, 1981).

Para a vertente holística tal cisão já não ocorreria, uma vez que esta almeja a unidade mente/corpo. Entretanto, a concepção holística, segundo De Marco (2003), opera muito mais na teoria do que na atuação prática em psicossomática.

Para Zorzanelli (2011), para além das complexidades citadas nesse sintético histórico acerca do termo psicossomática, há ainda outras complicações. Esse termo foi retirado do Diagnostic and Statistical Manual of Mental Disorders - IV (DSM-IV) e da Classificação Internacional de Doenças - 10 (CID-10), uma vez que se entendia o adoecimento como processo global. Assim, toda doença seria psicossomática, não se podendo reservar tal termo apenas para quando o elemento psicológico estivesse evidente.

$\mathrm{O}$ que era anteriormente compreendido como transtorno psicossomático na CID-9, é encontrado na versão seguinte nos diagnósticos de transtornos somatoformes (F45), transtornos alimentares (F50), disfunção sexual (F52) e fatores psicológicos ou comportamentos associados a transtornos ou doença classificados em outros blocos (F54) (Catani, 2014; Organização Mundial de Saúde, 1993). A histeria, como compreendida pela psicanálise, perde também sua denominação tradicional na CID-10, passando a ser referida como transtorno dissociativo, indicada na classe geral de transtornos neuróticos, relacionados ao estresse e somatoformes. O que é mantido de comum em relação ao que era conhecido como psicossomática e histeria é a noção da presença de sintomas físicos decorrentes de uma condição médica, mas que não podem ser totalmente explicados por essa condição ou por outro transtorno psiquiátrico. No DSM-V, a compreensão desse tipo de sintoma vem classificada como sintomas somáticos e transtornos relacionados. As queixas físicas são a principal característica desse grupamento do manual, que resultam em buscas incessantes por diagnóstico e cuidado, bem como em 
sofrimento e prejuízos generalizados na vida do indivíduo (American Psychiatric Association, 2014; Catani, 2014). Segundo De Gucht e Maes (2006), essas terminologias se aglutinam para designar: (a) uma expressão somática que implica relação causal entre emoções e somatização; (b) uma categoria diagnóstica em que múltiplos sintomas se alinham a diferentes órgãos; e (c) síndromes somáticas funcionais em que sintomas específicos são agrupados.

As alcunhas médicas para o fenômeno da falta de achados orgânicos têm sido, assim, alteradas, diferenciando-se de acordo com as áreas médicas em que são utilizadas. Para Bombana (2006), enquanto a psiquiatria utiliza transtornos somatoformes, a clínica médica faz uso de síndromes somáticas funcionais. No entanto, mesmo dentro de uma mesma área médica, os termos podem ser controversos (Tófoli, Andrade, \& Fontes, 2011).

A compreensão binária de que algumas entidades somáticas têm gênese psicológica ou que eventos orgânicos influenciam processos psicológicos implica, segundo Trombini e Baldoni (2004), na manutenção de uma compreensão dualista entre mente/corpo. Isso é algo muito criticado para as diversas concepções de psicossomática, embora seja raciocínio comum ao modelo biomédico que, imperando na área médica, passa a permear também o trabalho neste campo.

No modelo biomédico, a doença depende da descoberta de substratos anatômicos e fisiopatológicos cuja determinação é dada pelo médico e não pelo doente. A nova e sofisticada tecnologia contribui, igualmente, para a manutenção desse foco ao assumir um papel importante no diagnóstico, contudo desencadeia outra dificuldade: a relação pessoal entre médico e paciente acaba por perder sua importância. $\mathrm{O}$ encontro do médico com o doente ocorre unicamente na medida em que este é portador de uma lesão inscrita no interior do seu corpo, identificada não a partir da sua percepção, mas em função de uma norma exterior a ele (Fernandes, 1993; Lima \& Verdi 2015; Ugarte \& Acioly, 2014).

A atuação médica sob essa perspectiva e o modelo biomédico têm sido alvos de críticas, cada vez mais constantes, que versam, sobremaneira, acerca da forma com que o paciente é tratado, chegando a ser visto como um objeto. $\mathrm{O}$ uso exagerado do tecnicismo e de um vocabulário pertencente somente aos médicos, o abuso da medicalização, a falta de organização com relação aos horários das consultas e as dificuldades relacionadas à comunicação são alguns exemplos de aspectos focados na reflexão sobre a prática médica (Caprara \& Franco, 1999; Caprara \& Rodrigues, 2004; Fernandes, 1993).

Desde a segunda metade do século XX, a conduta médica vem sendo repensada a partir de diferentes perspectivas, destacando-se, entre elas, as de Jaspers e Balint (Caprara \& Franco, 1999) e Perestrello (1982) no Brasil. As propostas atêm-se, essencialmente, à revisão do olhar lançado para a pessoa que busca ajuda e, a partir desta, no repensar das possibilidades para seu cuidado. Trata-se de uma tentativa de humanização da medicina e, em particular, da relação existente entre médico e paciente, sensibilizando aquele para o sofrimento deste. É também sob o termo psicossomática que o tema da relação médico-paciente tem sido estudado, como ressalta Mello Filho (2002), ao referir que, sob esse conceito, agrupam-se desde atividades de ensino e/ou práticas de saúde até os cuidados com as relações entre médico, pacientes e familiares - atividades, por vezes, também designadas como da área da psicologia médica, como para Aragaki e Spink (2009).

Frente a esse complexo mosaico conceitual em que se configura a psicossomática, questiona-se, neste estudo, como se dá a inserção do cuidado à dimensão psicológica de pacientes considerados psicossomáticos por médicos que os atendem em consultórios, ambulatórios e prontos socorros. Como os profissionais da saúde compreendem essa dimensão e como se relacionam com seus pacientes? Com o objetivo de iluminar possíveis respostas, buscou-se compreender fenomenologicamente a vivência do médico no cuidado com pacientes por eles considerados psicossomáticos.

\section{Método}

O método utilizado na realização deste estudo situa-se em uma perspectiva fenomenológica de pesquisa qualitativa, uma vez que o objetivo do mesmo é captar a essência da experiência de médicos ao atender pacientes considerados por eles psicossomáticos. Um estudo fenomenológico descreve o significado das experiências vividas pelos indivíduos acerca de um conceito ou de um fenômeno, podendo valorizar principalmente as experiências individuais com a finalidade de determinar o que cada uma significa para os que a vivenciaram e podem descrevê-la. É a partir das descrições particulares que significados universais são derivados, indicando as essências das estruturas da experiência (Moustakas, 1994). Sendo assim, a metodologia fenomenológica, entre as diversas metodologias de pesquisa qualitativa, por manter seu foco na consciência e no conteúdo da experiência consciente e na profundidade da experiência vivida, conduz a um trabalho com pequeno número de participantes - "a pequena e intencional amostra" (Connelly, 2010, p.127) - que, na presente pesquisa, concretiza-se por entrevistas com quatro profissionais de medicina que atuam na rede hospitalar de uma instituição privada no interior do estado de São Paulo.

Trata-se de amostra construída por conveniência. Foram entrevistados médicos que, no ambiente de trabalho, ao serem perguntados se atendiam pacientes que consideravam psicossomáticos, responderam afirmativamente. Os participantes do estudo são duas mulheres e dois homens, aqui nomeados ficticiamente por Rosa, Marina, Alfredo e Gabriel, escolhidos pela diversidade de suas práticas profissionais: experiência em instituições privadas e públicas; atuação primária, secundária e terciária; e pela heterogenia do tempo de formado. Este, quando das entrevistas, variava entre seis e vinte e sete anos.

Foi realizado um encontro com cada participante e a entrevista foi do tipo aberta, semidirigida, iniciada com um convite/pergunta disparador:

Estou fazendo uma pesquisa sobre processos psicossomáticos. Por saber que se trata de um campo complexo em que se mesclam conhecimentos de medicina e psicologia, eu gostaria de saber como é sua experiência nesta área. Como foilé para você atender uma pessoa com este diagnóstico? 
$\mathrm{Na}$ elaboração do projeto desta pesquisa, teve-se o cuidado de delinear aspectos que, se não fossem abordados diretamente pelos participantes, ser-lhes-iam questionados no momento mais adequado de seu discurso. São tópicos abordados de forma a fomentar um relato mais subjetivo de suas práticas, sem deixar de lado a dimensão objetiva de sua formação. Embora sinalizados como perguntas, são assim utilizados apenas se necessário, uma vez que não compõem um questionário:

- Como o profissional lida com este paciente?

- De que maneira o percebe?

- Como se mobiliza emocionalmente com esta situação?

- Qual aprendizagem sobre psicossomática teve anteriormente para o cuidado destes pacientes?

Para a realização das entrevistas, a entrevistadora entrou em contato com os participantes, descrevendo os objetivos da pesquisa e como esta se daria caso resolvessem participar. Mediante a concordância, marcou-se um horário e local para a realização da entrevista. Dois profissionais se disponibilizaram para a entrevista, mas não compareceram às mesmas nos diversos horários em que foram remarcadas. A entrevista com aqueles que compareceram como haviam combinado foi iniciada somente após a leitura e assinatura do Termo de Consentimento Livre e Esclarecido por parte do entrevistado, bem como do esclarecimento de eventuais dúvidas. A pesquisa teve a aprovação do Comitê de Ética da Pontifícia Universidade Católica de Campinas, sob o número $604 / 06$. Foi utilizado um gravador - com consentimento dos entrevistados - para o registro das entrevistas, que posteriormente foram transcritas.

As entrevistas foram analisadas tendo como base a proposta feita por Amatuzzi (2003) para a análise fenomenológica, que segue os seguintes passos:

- A partir de uma leitura cuidadosa da transcrição de cada entrevista, captou-se o significado da vivência, buscando, na expressão dos elementos do vivido, respostas ao problema da pesquisa.

- A seguir, os elementos do vivido de cada uma das entrevistas foram agrupados de acordo com suas afinidades temáticas.

- Cada um desses agrupamentos temáticos foi descrito, visando à elaboração posterior de uma síntese geral. Contudo, no momento dessa síntese, constatou-se a existência de duas grandes temáticas que mereciam considerações aprofundadas, sendo, portanto, separadas para a elaboração de dois artigos diferentes: (a) compreensão do fenômeno psicossomático (Alves \& Espinha, 2014) e (b) a atuação médica com pacientes considerados psicossomáticos, foco do atual trabalho.

- Para o presente estudo, elaborou-se uma síntese geral do vivido, em que constavam os elementos comuns, bem como os diversificados acerca de suas vivências referidas à atuação médica.

\section{Resultados e Discussão}

Os participantes deste estudo relatam todo o percurso de atendimento que estabelecem com pacientes considerados por eles psicossomáticos. Trata-se de um caminho, provavelmente, muito pouco diferenciado daquele que estruturam com pacientes que apresentam quaisquer outras queixas, uma vez que estão imersos em uma prática médica cujo modelo predominante é o biomédico, que solicita do médico a busca pelas causas dos sintomas e a eliminação destes, ou seja, a cura da doença que os produz.

A mesma conduta de atendimento é traçada para pacientes que consideram psicossomáticos. Faz-se necessário compreender a doença, suas causas e sua natureza para, então, propor uma terapêutica. Rosa, Marina, Gabriel e Alfredo discorrem, ao longo das entrevistas, sobre informações objetivas, aspectos relativos à percepção dos pacientes e também sobre os sentimentos despertados na relação com os mesmos. Eles relatam como constatam ser o indivíduo um paciente psicossomático; como, na sequência, mobilizam-se diante dessa constatação; como reorganizam a relação médico-paciente a partir de então, a fim de tentar algumas terapêuticas e como evidenciam seu despreparo na abordagem do tema.

O diagnóstico do paciente como psicossomático, a mobilização, a reorganização da relação e a tentativa terapêutica encadeiam o processo vivencial e o discurso desses médicos, que é atravessado continuamente pela descrição de seu despreparo. Os passos descritivos de seus processos são aqui apresentados como as categorias constituintes de suas condutas médicas.

\section{O Diagnóstico do Paciente como Psicossomático}

Para qualquer paciente que procure os médicos participantes do estudo para uma consulta médica, seja em consultório, ambulatório ou mesmo no pronto socorro, eles, primeiramente, realizam a escuta da queixa. Essa escuta é dirigida e segue um protocolo, objetivando não a compreensão do paciente, mas sim de sua doença. Trata-se de um arranjo taxonômico que estabelecerá um significado para o conjunto de informações obtidas tanto por meio da linguagem propedêutica, com o uso da anamnese, como também pela apreensão de sinais e sintomas visíveis - a semiotécnica -, em que os dados obtidos pelos procedimentos de ausculta e palpação serão acrescentados aos dados levantados na anamnese.

Os participantes do estudo relatam estabelecer, rapidamente e por meio dessa escuta "protocolar", uma rotina habitual: exames clínicos, exames de laboratório e anamnese, entre outros recursos utilizados para se chegar ao diagnóstico, mesmo que a hipótese de problema psicológico se apresente logo de início, como relata Rosa:

Dentro da medicina, primeiro a gente tem que afastar tudo que existe, mesmo que o paciente chegue com uma hipótese diagnóstica ou um histórico psiquiátrico/psicológico, é preciso afastar qualquer morbidade e mortalidade do ponto de vista físico. Você afasta com exames e anamnese, depois de tudo, aí se pode pensar que é psicológico ou psicossomático.

Alfredo, mesmo após referir ser mais importante que o diagnóstico a compreensão da pessoa, diz entender o paciente como psicossomático ao diferenciar seus sintomas dos de outras doenças. Realiza, portanto, um diagnóstico, mesmo que não fundamentado pela rotina protocolar: " $E$ 
diferente daquela pessoa que chega aqui e fala: 'eu vim aqui porque estou com dor no joelho. Quando a gente fala de psicossomática são pessoas poliqueixosas".

Eles executam, desse modo, uma prática reconhecida por dar legitimidade social à medicina em sua função de resposta ao sofrimento humano - o ato diagnóstico -, que tem por componente-chave o reconhecimento imediato de um agregado de sinais e não a apreensão de sua totalidade (Camargo Jr., 2003). O fio condutor da atuação médica é ditado pela crença de que a resolução do problema do paciente se dará por um correto diagnóstico seguido de um efetivo tratamento, levando o médico a duas grandes tomadas de decisão: o diagnóstico e o tratamento.

A relação médico-paciente se constitui, então, por um diálogo marcado pela exploração de sinais, sintomas e resultados laboratoriais, mostrando-se uma atuação ditada pelo binômio 'queixa-conduta' em que não se exploram características psicossociais, culturais e familiares dos pacientes, uma vez que a finalidade da conduta parece ser a de tomar a queixa como sinal e fio condutor do tratamento, mantendo, desse modo, o estatuto ontológico da doença e estabelecendo práticas por vezes repetitivas e que não darão conta das singularidades da relação médico-paciente (Aciole, 2006; Mello Filho, 2007; Zorzanelli, 2011).

Este "ritual" de atendimento, em que o paciente é questionado, examinado, diagnosticado e, por fim, tratado, parece, entretanto, estar incorporado à cultura ocidental para além da esfera médica. Essa prática é alimentadora e reforçadora da ideia acerca do processo de "cura", de forma que os pacientes mostram um imaginário composto de noções reificadas sobre o mesmo (Aciole, 2006; Zorzanelli, 2011). Os pacientes esperam ser diagnosticados e ter a causa de suas doenças encontrada a fim de que possam ser tratados, como relatam os participantes do estudo, que também percebem a dificuldade de seus pacientes em entender aquilo que sentem e que não tem origem física: "é difícil fazer o cara entender que não é só tomar o remédio e que ele tem que cuidar de outras coisas" (Marina). Rosa menciona que é preciso provar por meio dos exames que a pessoa não tem nenhum problema orgânico para que a mesma acredite no médico. Este é um fenômeno que pode ser compreendido como decorrente da complementaridade entre médico e paciente. Segundo Ortega e Zorzanelli (2010), a atitude do médico, bem como sua compreensão de psicossomática, determina os sintomas apresentados pelos pacientes, uma vez que eles não os aceitam como imaginários e, consequentemente, produzem-nos legitimados pela sua época e cultura.

A consequência é a assustadora constatação de que se está diante de um problema sem causa conhecida. É assustador tanto para o paciente quanto para o médico, pois ambos estão imersos em uma cultura em que o modelo médico dita que a descoberta da causa é o caminho para a resolução do problema e, uma vez que este não tem causa, pode, consequentemente, não ter solução.

\section{A Mobilização}

A percepção da presença de um componente "emocional" na doença mobiliza os médicos de diversos modos e essa mobilização marca o eixo de conduta dos mesmos. Ainda durante o diagnóstico, surge um grande receio em se desconsiderar uma doença orgânica não conhecida, tomando-a por uma doença de ordem emocional. Como refere Rosa, a preocupação é: "não comer bola" e se certificar completamente da inexistência de causas orgânicas, o que também descreve Gabriel, que opta por não encaminhar o paciente a psiquiatras e psicólogos, com o objetivo de garantir não ter deixado de cuidar de uma possível doença física:

Eu encaminho para um clínico (...). É melhor você descartar outras coisas. Por exemplo, você hoje tem patologias descobertas que antes eram desconhecidas. Então, você acha que o paciente está ficando louco, mas não é isso. E o médico daquela área consegue identificar isso melhor do que eu.

O que parece mobilizá-los é uma questão de segurança e controle. Sentir-se sem recursos, quer de conhecimentos quer de tecnologia, faz surgir o medo de não ter o controle sobre o diagnóstico. A crença de que podem ser controlados eventos incontroláveis da vida e de que, pela via do conhecimento ou da tecnologia, pode-se antecipar algo oculto, predizendo depois o futuro - dar o prognóstico -, parece se desconstruir diante do manejo desses pacientes:

Encarar esse paciente é também ter que se encarar. Às vezes, a dificuldade que ele está enfrentando é também aquela que você tem enquanto profissional. Ai fica difícil, como você vai orientar o outro, amparar, não dizer o que fazer, mas dar todo o suporte para que ele tente resolver essa situação da melhor maneira? (Rosa)

O desamparo manifestado por Rosa é enfatizado por Marina e conceituado como um despreparo:

Puxa, você está fazendo o certo, que é o melhor que você pode fazer, mas para ele não vai resolver! Não é aquilo que vai melhorar ele. Eu nem tenho conhecimento para isso, para de repente poder ajudar. (...). Agora é muito ruim, porque você não consegue ajudar a pessoa e isso me angustia. Você vê que a pessoa está voltando várias vezes é porque você não está conseguindo.

Rosa e Marina não estão se referindo a um fenômeno novo ou sequer exclusivo da abordagem ao paciente psicossomático. Muitos autores, e já há muitos anos, vêm constatando e analisando que esse fenômeno decorre de uma formação médica incompleta (Aciole, 2006; Fernandes, 1993; Grosseman \& Stoll, 2008; Zorzanelli, 2011). Eles apontam que os médicos não exploram aspectos psicológicos de seus pacientes, como medo e ansiedade, por exemplo, por não receberem preparo para isso durante a formação acadêmica. Tal falta de preparo é referida por eles de igual forma, mesmo tendo eles diferentes anos de formação. Eles referem não ter tido, igualmente, oportunidades de autoconhecimento durante a formação, já que esta encontra-se centrada no modelo biomédico. Com o desenvolvimento da farmacologia, da imunologia, da bioquímica e da genética, o entendimento do contexto em que o paciente está inserido vai desaparecendo, provocando um olhar fragmentado do ser humano (Caprara \& Rodrigues, 2004; Cassiano \& Ávila, 2007; Rosemberg \& Minayo, 2001), como revela Rosa em seu discurso:

Mas a maioria dos médicos tem que ter algo palpável, pois, quando foge do que é palpável e do que você aprendeu, foge também da sua capacidade de tratar. É uma dificuldade de todo mundo (...) Causa uma sensação no médico de incapacidade, 
como eu tiro uma dor com dipirona, mas eu não tiro uma dor aguda no peito de repente, de mágoa ou tristeza? Você se sente incapaz.

\section{A Reorganização da Relação}

Depois de se deparar com "pistas" que não acusam aquilo que estão acostumados a detectar e, após, por vezes, terem até refeito os exames, os médicos chegam à conclusão de que a doença daquele paciente não tem causa orgânica. Mas, mesmo não tendo ferramentas para lidar com a situação, não desistem do paciente, como alguns estudiosos referem ser possível ao ressaltarem que o modelo biomédico pode tornar cada vez mais desinteressante a experiência do paciente e o entendimento do contexto em que ele está inserido (Caprara \& Rodrigues, 2004; Rosemberg \& Minayo, 2001). Os participantes do estudo, entretanto, não só não desistem do paciente, como tentam rever a relação estabelecida com ele. Eles se tornam mais atentos ao humor do paciente, à frequência com que ele retorna às consultas e às reações que porventura acompanham a dor, chegando a questionálo acerca de problemas pessoais ou situações estressantes.

Essas questões, porém, são feitas não na linha de um maior interesse pela pessoa do paciente, pelo contexto em que vive ou pelos significados que atribui a seu vivido. Os aspectos de ordem subjetiva são verificados apenas enquanto sinais "para a comprovação de que algo do indivíduo está aquém do esperado, comparando-o à média padrão do comportamento da normalidade dentro do espaço histórico cultural onde se insere" (Baroni, Vargas, \& Caponi, 2010, p.72). Trata-se do estabelecimento de uma relação médicopaciente valorizada muito mais pela possível obtenção de resultados do que propriamente como encontro humano. Porém, esta parece ser a única relação que conseguem estabelecer, visto terem partido de uma formação que os prepara para tratar um corpo e, entretanto, defrontam-se com o dono deste, um ser humano.

Em face dessas limitações e das condições de trabalho dos participantes, uma proposta como a de Perestrello (1982), para consultas mais demoradas que permitiriam um melhor vínculo com um paciente que, por conseguinte, procuraria menos o médico, absorvendo melhor suas orientações e medicações, não se realiza. Não é possível, porém, considerar que se trata aqui de uma indisponibilidade geral, uma vez que alguns dos participantes dizem gostar desses pacientes, enquanto outros mostram menor disponibilidade. Alguns profissionais têm a relação como encontro humano, enquanto outros, como mera ferramenta de trabalho (Costa \& Azevedo, 2010).

Para Alfredo, gostar do paciente é o que o fez optar pela profissão: "Eu gosto sim. Esse sempre foi o meu maior desejo pela medicina". O mesmo se dá com Rosa: "Mas geralmente eu não fujo destes pacientes. Eu gosto". E enquanto Marina relata não se sentir à vontade para perguntar demais sobre a vida pessoal do paciente, Gabriel disse conversar pouco e logo encaminhá-lo: “Eu converso um pouco, mas eu não vou a fundo".

De acordo com a mesma dificuldade relacional, os médicos evidenciam também a dificuldade em se deixar afetar pelo outro ao se referirem aos sentimentos despertados pelos pacientes. Marina diz esquecer-se dos pacientes que a marcam: "Na verdade, eu acho que isso é uma defesa. Eu saio daqui e esqueço. Eu não levo para casa". Alfredo diz que não se sente pessoalmente tocado pela situação dos pacientes: "Porque eu sei o que eu vou falar, sei o que vou perguntar e sei o que precisa ser feito. Não levo isso. Não sinto mais tanta piedade ou dó".

O acompanhamento médico que oferecem parece constituir-se por uma específica relação médico-paciente, construída de acordo com o modo como se avaliam (des) preparados e, também, em alinhamento com as condições de trabalho. Rosa e Marina evidenciam a inabilidade de relacionamento como pertinente a toda a categoria profissional (inserindo-se nela) e reconhecendo limites que apontam serem decorrentes de uma formação mais recente ou mais antiga. Para Marina, o "médico não sabe lidar com o emocional", enquanto para Rosa, "os médicos têm uma dificuldade de lidar com pacientes psicossomáticos, mais do que isso: uma dificuldade de tratar".

Simultaneamente às dificuldades que apresentam, eles indicam perceberem-se melhores que outros médicos, com uma postura muito mais próxima a do "ideal de médico" que mostram ter. É essencial, segundo eles, que o médico seja respeitoso, empático, paciente e bom ouvinte, características ditas de forma generalizada e que parecem construídas em decorrência da avaliação negativa da conduta dos colegas:

Têm médicos aí que são muito bons em diagnóstico, mas são horrorosos como pessoa. (...). Eu sei que grande parte dos colegas não está preocupada com isso. Não perde tempo de ouvir essa pessoa o que eu acho um grande erro. (Alfredo)

Gabriel, compartilhando a mesma compreensão, afirma: "na hora que a pessoa chega, a pessoa já passou num outro cara que é mal-educado. Se você trata ela com o respeito que ela merece, você já resolveu metade do problema do paciente". O discurso sobre a relação com os pacientes, delineado frente a esse ideal profissional, aparece em um estilo mais ou menos lírico, em que a relação médico-paciente é "despossuída de qualquer conteúdo positivo ou intrínseco às aptidões objetivamente exigidas para o cuidado dos doentes, portanto idealizado" (Fernandes, 1993, p. 21).

\section{A Tentativa Terapêutica}

Ao diagnosticarem seus pacientes como psicossomáticos, com sintomas que não indicam doenças de origem orgânica, e ao se defrontarem com situações para as quais não se sentem preparados, os participantes do estudo relatam tentar algumas terapêuticas. Eles mencionam primeiramente o encaminhamento para outros profissionais, desde médicos de outras especialidades (psiquiatria, clínica geral) até profissionais de psicologia e fisioterapia, bem como também para a religião. Os encaminhamentos dependem integralmente da convicção e dos valores que o próprio médico possui. Alguns acreditam que esses pacientes precisam conversar e se conhecer melhor e, assim, encaminham-nos para a psicologia. No entanto, quando esse tipo de serviço é inacessível aos pacientes ou pelo fato de que estes possam preferir um caminho mais fácil, o médico pode não se restringir ao 
encaminhamento para profissionais da área de psicologia. Alfredo aconselha ao paciente uma viagem ou que procure alguma religião: "Acho que você deveria procurar uma terapia ou tal religião ou vai viajar". O encaminhamento que ele faz: "Depende da situação socioeconômica da pessoa. Quando a gente sabe que a pessoa não tem condição eu peço para ela ir a várias religiões". Essa conduta enseja, de alguma forma, uma desvalorização dos aspectos subjetivos e relacionais dos elementos pertinentes ao psicológico, que estão raramente presentes ou valorizados na prática médica, permanecendo marginalizados sob a tutela dos profissionais especializados, como explicitam Rosemberg e Minayo (2001).

Antes ou até paralelamente a esses encaminhamentos, os médicos utilizam outra terapêutica: uma orientação que pensam que ajudará os pacientes a lidarem com a doença sem causa orgânica. Essa orientação, contudo, torna-se uma analogia ao medicamento, uma vez que é igualmente prescritiva. Sem levar em consideração a subjetividade da pessoa, é outro auxilio externo, como o remédio, e, por vezes, confundida com ele. Para Gabriel,

O médico tem que orientar. Então, essa é uma das funções do médico. (...) a gente tem que falar para o paciente o que ele tem mais ou menos, qual o caminho que ele vai seguir e se ele tem algo grave ou não. Esclarece as dúvidas com que ele chega em relação ao problema, o que pode diminuir a ansiedade e isso já melhora.

É uma conduta na qual prevalece o modelo informativo, em que o médico atua como técnico (Caprara \& Franco, 1999). Entretanto, essa orientação nem sempre cumpre a função de substituir a medicação. Ela é, por vezes, abandonada, cedendo-se ao medicamento, mesmo que alternativo. Rosa, para quem a analgesia é um risco potencial para pacientes que ela considera psicossomáticos, visto que pode viciá-los na substância, cede à pressão do paciente, trocando a substância por um fitoterápico que ela parece não considerar medicamento: "Então, nunca passo medicamento controlado num primeiro momento, então, oriento dieta, tirar estimulantes (...). Mas, se quiser tomar alguma coisa, ai eu passo fitoterápico, alguma coisa diferente de medicamento".

Marina e Alfredo apontam a mesma impotência em resistir ao uso de medicamentos. Para ela, "no pronto socorro, é complicado". Para ele, trata-se de uma condição sem saída: "Não tem alternativa, né?! Veja, por exemplo, a grande parte das pessoas depressivas ou as pessoas que não deram certo elas têm a síndrome do pânico. Como é que elas vão se livrar disso". Desse modo, a medicalização se configura como "mais um agente na constituição do sujeito sem conflitos e limites (...) a ação médica passa a ser mais um coadjuvante do sistema capitalístico e o remédio seu instrumento principal" (Rodrigues, 2003, p.19).

A conduta que os médicos apresentam quando se deparam com um paciente considerado psicossomático porta toda uma sistematização. Trata-se de uma conduta que evidencia o quanto se sentem despreparados e como culpam a fragilidade da formação obtida por suas dificuldades.

\section{O Despreparo Revelado}

Somente Rosa e Alfredo relatam ter tido contato com o tema da psicossomática ao longo da sua vida profissional. Ela estudou psicologia antes de cursar medicina, mas nunca atuou na área e não realizou nenhum estudo especifico sobre o assunto; ele, no período em que foi docente, "desenvolveu uma pesquisa próxima ao tema".

Segundo eles, é a prática cotidiana que lhes possibilita construir suas condutas com esse tipo de paciente. Todavia, o recurso à experiência própria não elimina a angústia ou a insegurança. Baseando-se sempre no modelo biomédico - sua grande referência - tentam, ainda no manejo da situação, confirmar os sintomas de seus pacientes face à classificação de doenças e/ou sintomas já "consagrados" pelo senso comum como psicossomáticos. A partir dessa perspectiva, "classificam" seus pacientes, como demonstra Rosa: "Na primeira consulta, eu já falo: sua falta de ar muito provavelmente é uma reação ao estresse, isso é uma coisa que você tenta colocar pra fora através do pulmão".

Desse modo, através de informações esparsas e pouco sistematizadas sobre psicossomática, vão construindo suas condutas de atendimento aos pacientes assim considerados. São condutas que, segundo Alfredo, estão baseadas na "minha experiência e o tempo de vida mesmo. E o tempo de atendimento (...). Não estudei o suficiente para ter uma abordagem, é na prática mesmo". A experiência pessoal na área médica é considerada a fonte de conhecimento mais importante, uma vez que a abordagem profissional é pragmática e dirigida aos resultados, como aponta Camargo Jr. (2003). Entretanto, Rosa, com menor tempo de formada do que Alfredo, faz ressalvas a este centramento na experiência pessoal. Para ela, formada mais recentemente, apontando ter recebido uma formação mais afeita à importância da cientificidade, o conhecimento científico é também importante: "Acho que convicção e história de vida também ajudam, mas conceitos e conteúdo, como reagir com este e com aquele paciente, ai vem da parte de estudo mesmo".

\section{Considerações Finais}

Como tem sido referido, os participantes do estudo sentemse despreparados para lidar com pacientes que consideram psicossomáticos e culpam uma formação médica mais antiga ou mais recente por não supri-los de conhecimentos e técnicas suficientes para o manejo destes pacientes. A constatação de falhas na formação médica não é algo exclusivo deles. Ao contrário, este é um fenômeno bastante estudado por diversos autores (Caprara \& Franco, 1999; Costa \& Azevedo, 2010; Fernandes, 1993; Coelho Filho, 2007), que apontam como elemento nefasto a predominância do modelo biomédico não apenas na formação, como em toda a cultura médica. Esse modelo enseja o foco da atuação médica meramente nos aspectos biológicos, deixando de lado, e incompreendidos, os aspectos psicológicos e sociais, de forma a não se atentar ao ser e sim ao corpo humano. O modelo biomédico de atenção à saúde encontra-se espraiado por toda a cultura ocidental. 
A sociedade é tanto sua consumidora, como reforçadora e produtora.

A concepção de corpo e mente separados que fundamenta esse modelo encontra-se entranhada também na expressão do paciente: ele quer saber o que causa seus sintomas e quer os melhores recursos tecnológicos para descobrir sua doença e tratá-la. Esse é o procedimento que ocorre não somente em suas próprias experiências de adoecimento, mas que constata por meio da mídia. Televisão, internet, revistas, jornais, livros e rádio apresentam matérias em que a cisão mente e corpo se mantém e, quando esses veículos tentam conjugar corpo e mente, acabam por apresentar ideias culpabilizantes ao paciente, como a de que a doença psicossomática decorre de uma deficiência pessoal para elaborar os conflitos psicológicos. A pessoa deveria, portanto, saber controlar racionalmente suas emoções. Desse modo, o que se constata é que a cisão corpo e mente é adensada e prolongada para uma cisão entre emoção e cognição, como prescrevem as matérias de revistas de saúde (Alves, Lima, Rivorêdo, \& Turato, 2012).

$\mathrm{O}$ relato dos participantes deste estudo sobre o que vivenciam ao tratar pacientes que consideram psicossomáticos dá ênfase às falhas na formação médica em subsidiar os profissionais a superar a dificuldade de manejo dos aspectos psicológicos de qualquer ordem, e não apenas os que são referidos como elementos psicogênicos do adoecimento. A percepção do que é psicológico por parte de médicos é considerada como indiscriminada, sendo fonte de sentidos e usos diversos (Aragaki \& Spink, 2009), que, no caso destes médicos, parece arremessá-los à angústia, fazendo com que se sintam despreparados para lidar com tudo aquilo que é de ordem psicológica, inclusive seus próprios sentimentos.

Os cursos de medicina, por sua vez, são reconhecidos por dar pouca atenção ao desenvolvimento da identidade e à assistência aos estudantes de medicina (Rodrigues, 2003), sendo reconhecida a importância de dar continência às emoções suscitadas durante o curso, uma vez que este exige lidar com sofrimento, dor e morte (Aragaki \& Spink, 2009). Todavia, cabe ressaltar que, além da ênfase que vem sendo dada à importância do ensino da relação médico-paciente - algo valioso para que a medicina resgate sua missão de tratar doentes e não apenas doenças -, é "o enfoque de como fazê-lo" que parece pouco explorado (Coelho Filho, 2007).

As dificuldades que estes médicos relatam ao lidar com aspectos psicológicos talvez não se restrinjam aos pacientes psicossomáticos, mas com estes se intensifique. Uma formação que melhor aborde os aspectos psicológicos e que lhes possibilite vivenciar experiências em que a subjetividade humana possa conjugar-se com a objetividade de suas práticas pode vir a ajudá-los não apenas a melhor cuidar de seus pacientes, mas também de si próprios no decorrer do trabalho, bem como facilitar sua compreensão sobre o fenômeno psicossomático.

\section{Referências}

Aciole, G. (2006). A Lei do Ato Médico: Notas sobre suas influências para a educação médica. Revista da Associação Médica Brasileira, 30(1),47-54.
Aisenstein, M. (2008). Beyond the dualism of psyche and soma. The Journal of the American Academy of Psychoanalysis and Dynamic Psychiatry, 36(1), 106-123.

Alves, V. L., \& Espinha, T. (2014). Compreensão do distúrbio psicossomático a partir da vivência de médicos. Interação em Psicologia, 18(1), 71-81.

Alves, V. L., Lima, D. D., Rivorêdo, C. R., \& Turato, E. R. (2012). Emoção e soma (des) conectadas em páginas de revista: As categorias temáticas do discurso prescritivo sobre os fenômenos da vida e da doença. Ciência e Saúde Coletiva, $18(2), 537-543$.

Amatuzzi, M. M. (2003). Pesquisa fenomenológica em psicologia. In M. A. Bruns \& A. Holanda (Orgs.), Psicologia e pesquisa fenomenológica: Reflexões e perspectivas (pp. 17-25). São Paulo: Alínea.

American Psychiatric Association. (2014). Manual diagnóstico e estatístico de transtornos mentais: DSM-5. Porto Alegre: Artmed

Aragaki, S. S., \& Spink, M. J. (2009). O lugar da psicologia na educação médica. Interface, 13(28), 85-98.

Baroni, D. P., Vargas, R. F., \& Caponi, S. N. (2010). Diagnóstico como nome próprio. Psicologia e Sociedade, 22(1), 70-77.

Bombana, J. B. (2006). Sintomas somáticos inexplicados clinicamente: Um campo impreciso entre a psiquiatria e a clínica médica. Journal Brasileiro de Psiquiatria, 55(4), 308-312.

Camargo Jr., K. R. (2003). Sobre palheiros, agulhas, doutores e o conhecimento médico: O estilo de pensamento dos clínicos. Cadernos de Saúde Pública, 19(4), 1163-1174.

Caprara, A., \& Franco, A. L. S. (1999). Relação paciente-médico: Para uma humanização da prática médica. Cadernos de Saúde Pública, 15(3), 647-654.

Caprara, A., \& Rodrigues, J. (2004). A relação assimétrica médicopaciente: Repensando o vínculo terapêutico. Ciência e Saúde Coletiva, 9(1), 139-146.

Cassiano, L. S. C., \& Ávila, L. (2007). Controvérsias sobre a somatização. Revista de Psiquiatria Clínica, 34(6), 278-284.

Catani, J. (2014). Histeria, transtornos somatoformes e sintomas somáticos: As múltiplas configurações do sofrimento psíquico no interior dos sistemas classificatórios. Jornal de Psicanálise, 47(86), 115-134.

Cerchiari, E. A. (2000). Psicossomática um estudo histórico e epistemológico. Psicologia Ciência e Profissão, 20(4), 64-79.

Coelho Filho, J. (2007). Relação médico-paciente: a essência perdida. Interface, 11(23), 631-633.

Connelly, L.M. (2010). What is phenomenology? Medsurg Nursing, 19(2),96-100.

Costa, F. D., \& Azevedo, R. C. (2010). Empatia, relação médicopaciente e formação em medicina: Um olhar qualitativo. Revista Brasileira de Educação Médica, 34(2), 261-269.

De Marco, M. (2003). A face humana da medicina. São Paulo: Casa do Psicólogo.

De Gucht, V., \& Fischler, B. (2002). Somatization: A critical review of conceptual and methodological issues. Psychosomatics, $43(1), 1-9$

De Gucht, V., \& Maes, S. (2006). Explaining medically unexplained symptoms: Toward a multidimensional, theorybased approach to somatization. Journal of Psychosomatic Research, 60(4), 349-352. 
Fernandes, J. C. (1993). A quem interessa a relação médico paciente? Cadernos de Saúde Pública, 9(1), 21-27.

Figueira, M. L., \& Ouakinin, S. (2008). From psychosomatic to psychological medicine: What's the future? Current Opinion in Psychiatry, 21(4), 412 - 416.

Grosseman, S., \& Stoll, C. (2008). O ensino-aprendizagem da relação médico-paciente: Estudo de caso com estudantes do último semestre do curso de medicina. Revista Brasileira de Educação Médica, 32(3), 301-308.

Heidbreder, E. (1981). Psicologias do século XX (5 $5^{\mathrm{a}}$ ed., L. S. Blandy, Trad.). São Paulo: Mestre Jou. (Trabalho original publicado em 1933)

Hoyos, M. L., Ochoa, D. A., \& Londoño, C. R. (2008) Revisión crítica del concepto "psicosomático" a la luz del dualismo mente-cuerpo. Pensamiento Psicológico, 4(10),137- 147

Lima, R. C. G. S., \& Verdi, M. I. M. (2015). Discursos de médicos de família brasileiros e italianos sobre autonomia na perspectiva bioética. Saúde e Sociedade, 24(3), 1021-1032.

Lipowski, Z. J. (1986). Psychosomatic medicine: Past and present: Current state. Canadian Journal of Psychiatry, 31(1), 2-7.

Lyketsos, C. G., Huyse, F. J., Gitlin, D. F., \& Levenson, J. L. (2006). Psychosomatic medicine: A new psychiatric subspecialty in the U.S. focused on the interface between psychiatry and medicine. European Journal of Psychiatry, 20(3), 165-171.

Mello Filho, J. (2002). Concepção psicossomática: Visão atual. São Paulo: Casa do Psicólogo.

Moustakas, C. (1994). Phenomenological research methods. Thousands Oaks, CA: Sage.

Organização Mundial da Saúde. (1993). Classificação de transtornos mentais e de comportamento da CID-10: Descrições, clínicas e diretrizes diagnósticas. Porto Alegre: Artes Médicas
Ortega, F., \& Zorzanelli, R. (2010). Corpo em evidência. Rio de Janeiro: Civilização Brasileira.

Peres, R., Caropreso, F., \& Simanke, R. (2015). A noção de representação em psicanálise: Da metapsicologia à psicossomática. Psicologia Clínica, 27(1), 161-174.

Perestrello, D. (1982). A medicina da pessoa. Rio de Janeiro: Atheneu.

Rodrigues, J. T. (2003). A medicação como única resposta: Uma miragem do contemporâneo. Psicologia em Estudo, 8(1), $13-22$.

Rosemberg, B., \& Minayo, M. C. (2001). A experiência complexa e os olhares reducionistas. Ciência e Saúde Coletiva, 6(1), 115-123.

Tófoli, L. F., Andrade, L. H., \& Fortes, S. (2011). Somatização na América Latina: Uma revisão sobre a classificação de transtornos somatoformes, síndromes funcionais e sintomas sem explicação médica: Classificação de transtornos somatoformes, síndromes funcionais e sintomas sem explicação médica. Revista Brasileira de Psiquiatria, 33(Supl I), 59-69.

Trombini, G., \& Baldoni, F. (2004). Distúrbios psicossomáticos: Como restabelecer o equilibrio entre mente e corpo. São Paulo: Edições Loyola.

Turato, E. R. (2008). Tratado da metodologia da pesquisa clínico qualitativa. Petrópolis: Vozes.

Ugarte, O. N., \& Acioly, M. A. (2014). O princípio da autonomia no Brasil: Discutir é preciso... Revista do Colégio Brasileiro de Cirurgiões, 41(5), 274-277.

Volich, R. M. (2005). Psicossomática: De Hipócrates à psicanálise. São Paulo: Casa do Psicólogo.

Zorzanelli, R. (2011). Sobre os diagnósticos das doenças sem explicação médica. Psicologia em Estudo, 16(1),25-31.

Recebido em 19.06.2013

Primeira decisão editorial em 17.02.2016

Versão final em 23.03.2016

Aceito em 11.05.2016 